\title{
Cys-SH based quantitative redox proteomics of salt induced response in sugar beet monosomic addition line M14
}

Jinna $\mathrm{Li}^{1,2 \dagger}{ }^{,}$Kun Wang ${ }^{3+}$, Meichao $\mathrm{Ji}^{2}$, Tingyue Zhang ${ }^{2}$, Chao Yang ${ }^{2}, \mathrm{He} \mathrm{Liu}^{2}$, Sixue Chen ${ }^{4,5}$, Hongli Li ${ }^{2,3^{*}}$ and Haiying $\mathrm{Li}^{1,2,3^{*}}$

\begin{abstract}
Background: Salt stress is a major abiotic stress that limits plant growth, development and productivity. Studying the molecular mechanisms of salt stress tolerance may help to enhance crop productivity. Sugar beet monosomic addition line M14 exhibits tolerance to salt stress.

Results: In this work, the changes in the BVM14 proteome and redox proteome induced by salt stress were analyzed using a multiplex iodoTMTRAQ double labeling quantitative proteomics approach. A total of 80 proteins were differentially expressed under salt stress. Interestingly, A total of 48 redoxed peptides were identified for 42 potential redox-regulated proteins showed differential redox change under salt stress. A large proportion of the redox proteins were involved in photosynthesis, ROS homeostasis and other pathways. For example, ribulose bisphosphate carboxylase/oxygenase activase changed in its redox state after salt treatments. In addition, three redox proteins involved in regulation of ROS homeostasis were also changed in redox states. Transcription levels of eighteen differential proteins and redox proteins were profiled. (The proteomics data generated in this study have been submitted to the ProteomeXchange and can be accessed via username: reviewer_pxd027550@ebi.ac.uk, password: q9YNM1Pe and proteomeXchange\# PXD027550.)
\end{abstract}

Conclusions: The results showed involvement of protein redox modifications in BVM14 salt stress response and revealed the short-term salt responsive mechanisms. The knowledge may inform marker-based breeding effort of sugar beet and other crops for stress resilience and high yield.

Keywords: Sugar beet M14 line, Salt stress, Redox proteomics, iodoTMTRAQ, Molecular mechanisms

\section{Background}

Salinity is a global challenge to plant growth, agriculture and world food security (Yu et al. 2016; Hsu et al. 2009; Chang et al. 2012). When plants are subjected to salt stress, it can induce osmotic stress, ionic stress, oxidative

\footnotetext{
*Correspondence: Ihl_lcy@sina.com; Ivzh3000@sina.com

†Jinna Li, Kun Wang are co-first author

${ }^{1}$ Ministry of Education, School of Chemistry and Materials Science, Heilongjiang University, Harbin 150080, China

${ }^{2}$ Key Laboratory of Molecular Biology of Heilongjiang Province, College

of Life Sciences, Heilongjiang University, Harbin 150080, China

Full list of author information is available at the end of the article
}

stress and other secondary stress (Khan et al. 2007; Yang et al. 2018). Plants respond and adapt to adverse environments through a variety of physiological, biochemical and molecular processes (Howat et al. 2000; Xu et al. 2019). The protein stability, catalytic activity and interaction with other molecules were affected the posttranslational modifications of amino acid residues. Redox plays a multifaced role in regulates signaling, metabolic and developmental activities (Mock et al. 2016). One redox chemistry involves reversible oxidation/reduction of the sulfhydryl groups of protein cysteine residues (Cys-SH) that directly influence protein structures and functions (Heppner 
et al. 2018). Cysteine thiols can be oxidized in a variety of reactions (Baez et al. 2015). The redox posttranslational modifications (PTMs) include disulfide formation (S-S), S-glutathionylation (SSG), S-nitrosylation (SNO), S-sulfenylation $(\mathrm{SOH})$, and S-sulfhydration ( $\mathrm{SSH})$, all of these can be reduced to free thiols by cellular antioxidant systems (Ji et al. 2017; Claiborne et al. 2005; Poole et al. 2004; Gupta et al. 2013; Heppner et al. 2017). Reactive oxygen species (ROS) are generated in the course of salt stress. Two ROS scavenging systems are mainly responsible for alleviation of salt stress-induced oxidative stress, i.e., enzymatic antioxidant system (e.g., glutathione S-transferase (GST), glutaredoxin (GR), superoxide dismutase (SOD) and catalase (CAT)) and non-enzymatic antioxidant system (e.g., ascorbate (AsA) and glutathione (GSH)) (Dave et al. 2012; Farooq et al. 2016; Jung et al. 2019). Experimental and bioinformatic analyses of the cysteine redoxome have been conducted to identify cellular redox active cysteines and reveal the redox networks that include ROS generation, specific types of ROS, redox sensitive proteins, GSH-linked enzymes, and biological impact (Thamsen et al. 2011; Kemp et al. 2008; Kitajima 2008; Kitajima et al. 2008). However, redox proteomic research in sugar beet response to salt stress is yet to be conducted.

Several salt stress proteomic studies in sugar beet have been reported. Wakeel A et al. identified nine proteins from sugar beet shoots and roots that changed significantly in abundance under salt stress (Wakeel et al. 2011). Sugar beet monosomic addition line M14 (hereafter named BvM14) was produced by crossing Beta vulgaris L. and B. corolliflora Zoss. It retains chromosome 9 of $B$. corolliflora Zoss in addition to the $B$. vulgaris $\mathrm{L}$. genome (Li et al. 2009). Our previous studies have demonstrated that the BvM14 plants can growth for seven days under $500 \mathrm{mM} \mathrm{NaCl}$, which caused significant abundance changes to 67 unique proteins (Yang et al. 2012). Quantitative proteomics of the $B v M 14$ under lower salt concentrations (200 and $400 \mathrm{mM} \mathrm{NaCl}$ ) revealed 75 differentially changed proteins in leaves and 43 differential proteins in roots (Yang et al. 2013). The data showed that enhancement of photosynthesis and energy metabolism, accumulation of osmolyte and antioxidant enzymes, and regulation of methionine metabolism and ion uptake/ exclusion were key processed underlying the salt stress responses. Furthermore, they compared gene transcription data with the corresponding protein data (Yang et al. 2013). Later, $\mathrm{Li}$ et al. analyzed the changes in BvM14 membrane proteome under salt stress (Li et al. 2015). In total, 50 proteins exhibited differential changes among the 274 identified membrane proteins. The proteins were mainly involved in transport, metabolism, protein synthesis, photosynthesis, protein folding and degradation, signal transduction, stress and defense, energy, and cell structure (Li et al. 2015). Clearly, the membrane proteomic research complemented previous work on the soluble proteins. To explore potential PTMs during the salt stress, Yu et al. studied the BvM14 proteome and phosphoproteome under salt stress, they identified 189 phosphoproteins and 2182 unique proteins (Yu et al. 2016). This study highlighted specific kinase signaling mechanisms underlying the $B v M 14$ response to salt stress. Interestingly, under $200 \mathrm{mM} \mathrm{NaCl}$ condition, proteins important for redox regulations such as GR and peroxiredoxin (PrxR) were both increased at the phosphorylation level (Yu et al. 2016). GR (also known as thioltransferase) can reduce glutathionylated proteins, and PrxR uses a similar thiol-based mechanism to reduce $\mathrm{H}_{2} \mathrm{O}_{2}$ (Yu et al. 2020).

Oxidative stress and redox regulation appear to be important processes of sugar beet salt stress response (Yang et al. 2013; Yu et al. 2016). To understand how redox regulation plays a role in the response of $B v M 14$ to salt stress, it is important to profile redox PTMs that occur to redox sensitive proteins. Most of the redox proteomics experiments showed changes in the protein thiol redox state do not address changes in the overall protein turnover. To overcome this potential complication, a double-labeling strategy iodoTMTRAQ was developed to integrate iodoacetyl (iodo)TMT reagents for profiling redox PTMs with the isobaric Tags for Relative and Absolute Quantitation (iTRAQ) reagents designed for quantifying total protein level changes (Parker et al. 2015). In this study, we apply the iodoTMTRAQ strategy to identify and quantify redox proteome and total proteome changes in $B v M 14$ line under short-term salt stress. The data have revealed new redox responsive proteins and their potential roles in the response to salt stress. The results have improved our understanding of redox responsive proteins in plants salt stress response.

\section{Materials and methods \\ Plant materials and $\mathrm{NaCl}$ treatment}

The sugar beet M14 seeds were sterilized with $70 \%(\mathrm{v} / \mathrm{v})$ ethanol, $0.1 \%(\mathrm{w} / \mathrm{w})$ mercurial chloride and $0.2 \%(\mathrm{w} / \mathrm{w})$ thiram, and then sown in vermiculite for germination. After one week, the seedlings were transferred to hydroponic medium of the Hoagland solution (Ghoulam et al. 2002). Seedlings were grown in a growth chamber under a $13 \mathrm{~h}$ light $/ 11 \mathrm{~h}$ dark cycle, $25 / 20^{\circ} \mathrm{Cday} /$ night temperature, $450 \mu \mathrm{mol} \mathrm{m}^{-2} \mathrm{~s}^{-1}$ light intensity and a relative humidity of $70 \%$. Three-week-old seedlings were divided into two groups: (1) control group (without $\mathrm{NaCl}$ ); (2) treatment group (200 mM and $400 \mathrm{mM} \mathrm{NaCl}$ for 5,10 , $20,30,60,90 \mathrm{~min})$. The $\mathrm{NaCl}$ concentrations were chosen according to a previous report showing that the M14 
line can tolerate up to $500 \mathrm{mM} \mathrm{NaCl}$ (Yang et al. 2012). Leaves of control and treated M14 seedlings were harvested directly into liquid nitrogen and stored in $-80^{\circ} \mathrm{C}$. At least three independent biological replicates of control and treated samples were analyzed in all the experiments.

\section{Ascorbic acid (AsA) and glutathione (GSH) content assay}

For ascorbic acid (AsA) and glutathione (GSH) content assays, $0.1 \mathrm{~g}$ leaf material was ground in $1 \mathrm{~mL}$ reagent from either the ascorbic acid assay kit (AsA-1-W) or the glutathione assay kit (GSH-1-W) from Comin Inc (Harbin, China). After centrifugation at $8000 \mathrm{rpm}, 4{ }^{\circ} \mathrm{C}$ for $20 \mathrm{~min}$, the supernatant was used for AsA and GSH content assays according to manufacturer instructions. Three independent biological replicates were prepared for each sample.

\section{Protein extraction and blockage of free thiols}

Protein extraction from the $B v M 14$ leaves was performed according to a phenol extraction method (Ghoulam et al. 2002). Briefly, 2 g M14 leaves were ground into a fine powder in liquid nitrogen and suspended in $1.25 \mathrm{~mL}$ Tris saturated phenol (pH8.8) and $1.25 \mathrm{~mL}$ phenol extraction buffer (900 mM sucrose, $100 \mathrm{mM}$ Tris- $\mathrm{HCl}$ (pH8.8), $1 \mathrm{mM}$ PMSF, $20 \mathrm{mM}$ N-ethylmaleimide (NEM), $10 \mathrm{mM}$ EDTA) (Parker et al. 2015; Yuan et al. 2019). NEM will irreversibly block free cysteine thiols during the protein extraction process. Protein samples were prepared from three independent biological replicates, and protein concentration was determined using a 2D Quant kit (GE Healthcare, USA) with BSA $(2 \mathrm{mg} / \mathrm{mL})$ as the standard (Parker et al. 2012).

\section{iodoTMT labeling and trypsin digestion}

Reduced thiols for reverse labeling were generated by incubating the protein samples with $5 \mathrm{mM}$ tris (2-carboxyethyl) phosphine for $1 \mathrm{~h}$ at $50{ }^{\circ} \mathrm{C}$. We labeled 0,30 and 60 min control samples with 126, 128 and 130 iodoTMT reagents, and the salt treated samples with 127, 129 and 131 reagents, respectively. Labeling was performed at $37{ }^{\circ} \mathrm{C}$ for $2 \mathrm{~h}$ in the dark, then quenched with $0.5 \mathrm{M}$ DTT for $15 \mathrm{~min}$ at $37^{\circ} \mathrm{C}$ in the dark. Trypsin (Sequencing grade, Promega, Madison) was added with an enzyme to protein ratio of $1: 50(\mathrm{w} / \mathrm{w})$ and the digestion was performed at $37{ }^{\circ} \mathrm{C}$ overnight (Parker et al. 2012). Peptides were cleaned up with $\mathrm{C} 18$ desalting columns (The Nest Group Inc., Southborough, MA) and lyophilized to dryness.

\section{iTRAQ labeling, strong cation exchange fraction and LC- MS/MS}

The C18 cleaned peptides were labeled with iTRAQ reagents according to the manufacturer's protocol (AB Sciex
Inc., Framingham, MA, USA). The 0, 30 and 60 min control samples were labeled with reporter tags 113, 115 and 117, and the treatment samples were labeled with reporter tags 114, 116 and 118, respectively. The labeling was conducted at $37^{\circ} \mathrm{C}$ for $2 \mathrm{~h}$, and the labeled peptides were desalted according to a previous procedure (Yu et al. 2016; Parker et al. 2012). LC-MS/MS was carried on an Easy-nLC 1000 connected to a Q-Exactive Plus MS/MS system (Thermo Fisher Scientific, Bremen, Germany). The peptides were loaded onto an Acclaim Pepmap 100 pre-column and separated on a PepMap RSLC analytical column, followed by tandem mass spectrometry according to the method of Yu et al. (Yu et al. 2016).

\section{Data analysis}

The MS/MS data were searched against the $B$. vulgaris database (52,749 entries) using Proteome Discoverer 2.1 (Thermo Fisher Scientific, Bremen, Germany) with the parameters from a previous publication (Yin et al. 2017). We used iodoTMT and iTRAQ reporter ion peak intensities for relative quantification with unique peptides. Each iodoTMT tag was exported as unique peptide peak intensities, and ratios were calculated accordingly peak intensity values. We used student's $t$-test conducted between the fold change of iodoTMT labeled peptides and the fold change of the corresponding proteins based on iTRAQ. The protein should be quantified in all the three biological replicates. The protein fold change $>1.2$ or $<0.8$ ( $\mathrm{p}$-value $<0.05$ ) were used to determine significant redox or total protein level changes. All the proteins were searched by NCBInr and Uniprot (http://www.ebi. uniprot.org) for functional annotation, subcellular location and gene ID numbers of the homologous proteins. Gene ontology (GO) (http://geneontology.org) terms and imported Kyoto Encyclopedia of Genes and Genomes (KEGG) (https://www.kegg.jp) database were used for Blast2GO analysis (Conesa et al. 2005). The functional enrichment analysis was performed according to Yu's procedure (Yu et al. 2016).

\section{Quantitative Real time PCR analysis}

Total RNA was isolated from frozen samples using a TRIZOL reagent (Invitrogen). By adding DNase I, genomic DNA was removed and cDNA was synthesized using the PrimeScript ${ }^{\mathrm{TM}}$ RT Master Mix (Perfect Real Time) (TakaRa, Shiga, Japan). Gene specific primers of the target genes were designed using online Primer3 Plus according to a previous report (Untergasser et al. 2007). Quantitative RT-PCR analysis was performed in a $30 \mu \mathrm{L}$ volume containing $15 \mu \mathrm{L}$ of Power UpTM SYBRTM green master (Applied Biosystems, Vernon, CA, USA), $3 \mu \mathrm{L}$ of 20 -fold diluted cDNA, $3 \mu \mathrm{L}$ of each gene-specific primer, and $9 \mu \mathrm{L}$ of $d_{d d H_{2}} \mathrm{O}$. The 
PCR conditions were as follows: $95{ }^{\circ} \mathrm{C}$ for $3 \mathrm{~min}$; $95{ }^{\circ} \mathrm{C}$ for $15 \mathrm{~s}, 59^{\circ} \mathrm{C}$ for $30 \mathrm{~s}, 40$ cycles. Three biological replicates were used for each sample. Reaction was conducted on an ABI7500 (Applied Biosystems, Vernon, CA, USA). All the data were analyzed using ABI7500 software (Applied Biosystems, Vernon, CA, USA) and Graphpad Prism 6.01. The comparative CT method $\left(2^{-\Delta \Delta \mathrm{CT}}\right)$ was used for relative quantification of gene transcripts. Each biological sample comprised of three technical repeats and each experiment was repeated three times (Pichon et al. 2017).

\section{Results}

Changes of AsA and GSH in BvM14 leaves under salt stress Recent studies showed that AsA and GSH are major antioxidants in plant salt stress response (Navrot et al. 2011; Lin et al. 2020; Khan et al. 2020), here we measured changes of two major antioxidants AsA and GSH at $0,5,10,20,30,60$ and $90 \mathrm{~min}$ after $0,200,400 \mathrm{mM}$ $\mathrm{NaCl}$ treatments. As shown in Fig. 1, under control conditions, the contents of AsA and GSH in BvM14 leaves maintained at fairly constant levels during the 90 min of assay time. Compared to control conditions, both the AsA and GSH contents reached maximum after $30 \mathrm{~min}$ of $200 \mathrm{mM} \mathrm{NaCl}$ stress. While after $60 \mathrm{~min}$ of $400 \mathrm{mM} \mathrm{NaCl}$ stress, both the AsA and GSH contents reached the peak level (Fig. 1). The results clearly showed that salt stress caused significant cellular redox changes as early as $10 \mathrm{~min}$ after the treatment. Based on the AsA and GSH changes, we selected samples collected at $30 \mathrm{~min}$ and $60 \mathrm{~min}$ of $200 \mathrm{mM}$ and $400 \mathrm{mM} \mathrm{NaCl}$ conditions, respectively, for iodoTMTRAQ-based redox proteomics.
Identification of differential proteins and different redox proteins in response to salt stress

Using iodoTMTRAQ LC-MS/MS and database searching, a total of 1290 proteins were identified in BvM14 leaves (Additional file 3: Table S1). Eighty proteins were differentially changed in abundance (based on iTRAQ reporter fold change $>1.2$, or $<0.8, \mathrm{p}<0.05$ ) in salt-treated samples compared to the control samples (Additional file 4: Table S2). Only four differential proteins were identified under the $200 \mathrm{mM} \mathrm{NaCl}$ treatment, while 77 were identified under the $400 \mathrm{mM} \mathrm{NaCl}$ treatment. Functional classification of the differential proteins revealed the following distribution: metabolism (6.3\%), protein synthesis $(27.4 \%)$, transport (6.3\%), stress and defense (2.5\%), ROS homeostasis (7.5\%), protein stability and turnover (5\%), photosynthesis (5\%), transcription related $(6.3 \%)$ and unknown (33.7\%) (Fig. 2A). The subcellular locations of the 80 differential proteins were classified to the chloroplast (32.7\%), cytoplasm (11.5\%), cytosol (1.9\%), mitochondrial (7.7\%), nuclear (42.4\%), plasma membrane (1.9\%) and vacuole (1.9\%) (Fig. 2B). Biological process, molecular functional and cell components were significantly enriched by AgriGO (Additional file 2: Fig. S2). And among these biological processes, the interesting terms included response to stimulus, response to stress, and so on, whereas the interesting molecular functions such as RNA binding, structural molecule activity.

Based on iodoTMT reporter intensities, we identified 42 proteins with significant redox changes in response to salt stress (Additional file 5: Table S3). Here are the functional categories of the differential redox proteins: metabolism (9.5\%), transport (16.7\%), biosynthesis (19.1\%), transcription related (2.4\%), signal transduction (4.8\%), stress and defense (2.4\%),
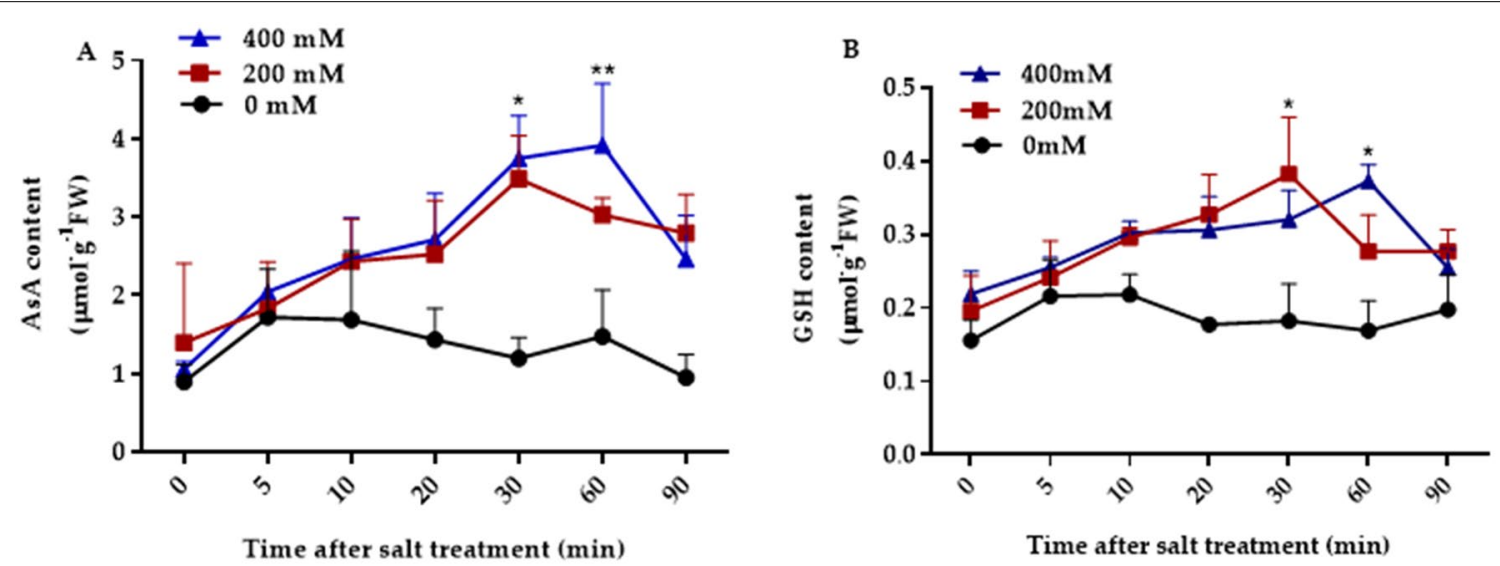

Fig.1 Temporal changes of AsA and GSH contents in leaves of BVM14 plants after salt stress treatments. A AsA contents under $200 \mathrm{mM}$ and $400 \mathrm{mM}$ $\mathrm{NaCl}$ stress. B GSH contents under $200 \mathrm{mM}$ and $400 \mathrm{mM} \mathrm{NaCl}$ stress. The values are the mean of three biological replicates from different samples with standard errors 


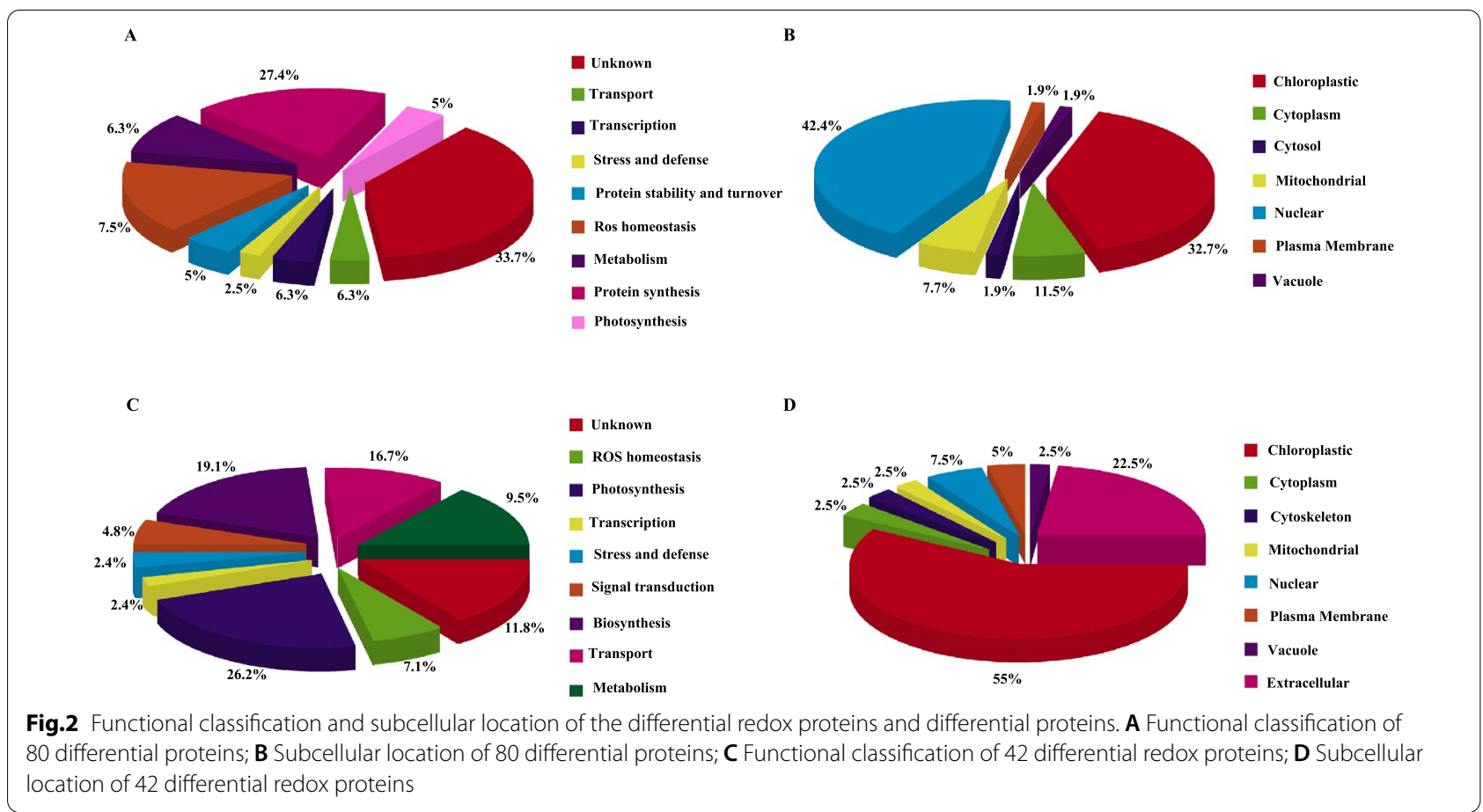

ROS homeostasis (7.1\%), photosynthesis (26.2\%) and unknown (11.8\%) (Fig. 2C). The subcellular localizations of the redox proteins were classified to the chloroplast $(55 \%)$, cytoplasm $(2.5 \%)$, cytoskeleton $(2.5 \%)$, mitochondrial $(2.5 \%)$, nuclear $(7.5 \%)$, plasma membrane $(5 \%)$, extracellular $(22.5 \%)$ and vacuole $(2.5 \%)$ (Fig. 2D). Biological process, molecular functional and cell components were significantly enriched by AgriGO (Additional file 1: Fig. S1). And among these biological processes, the interesting terms included response to stimulus, cellular process and so on, the molecular functions such as RNA binding, hydrolase activity. Among the 42 differential redox proteins, four were identified under $200 \mathrm{mM} \mathrm{NaCl}$ treatment, and 40 were identified under $400 \mathrm{mM} \mathrm{NaCl}$ treatment. There were 31 oxidized and 18 reduced cysteine residues in the redox proteins (Tables 1, 2).

\section{Mapping redox responsive cysteine residues in the BvM14 response to salt stress}

With the acquired MS/MS spectra, a total of 48 redox responsive peptides were identified in the 42 redox proteins (Additional file 5: Tables S3). In these peptides, the redox modified cysteine residues could be mapped. In Fig. 3, the MS/MS spectra of two redox peptides derived from ATP synthase $(731,341,013)$ and malate dehydrogenase $(731,329,081)$ were shown as examples (Fig. 3A, B).

\section{Transcriptional analysis of differential redox proteins and differential proteins}

To test how transcriptional level changes correlate with protein level and redox protein level, 11 differential proteins and seven differential redox protein were selected for analysis of their gene transcriptional level changes. The Real-time PCR primer sequences can be found in Additional file 6: Table S4. We categorized the transcriptional expression patterns of these genes into six groups based on their functions (Fig. 4, Additional file 6: Table S4). The first group proteins were involved in photosynthesis, including Rubisco LSU, Fd, Fd-1. The second group proteins were involved in ROS homeostasis, including Clot, Cys, PDIL1-1, CBSX3, EGC1, peroxidase (POD), Trx3-1, TrxH1, and TL29. The third group belonged to transport-related pathway including nsLTP, atpC protein. The fourth group DLD1 proteins belonged to metabolism. The fifth group RNase LE proteins belonged to biosynthesis. The last group proteins were stress and defense cascade, including DDR48 and DUF642.

Among the 18 genes encoding for the differential proteins, the transcriptional levels of 12 genes were coincide with the corresponding redox level trends and total protein level trends (Additional file 7: Table S5). The transcriptional levels of ATP synthase epsilon chain $(\operatorname{atpC})$, ferredoxin $(F d-1), P O D$ and thioredoxin-like 3-1 ( $\operatorname{Tr} x 3-$ 1) showed different trends with the corresponding redox changes, while the extracellular ribonuclease LE-like 


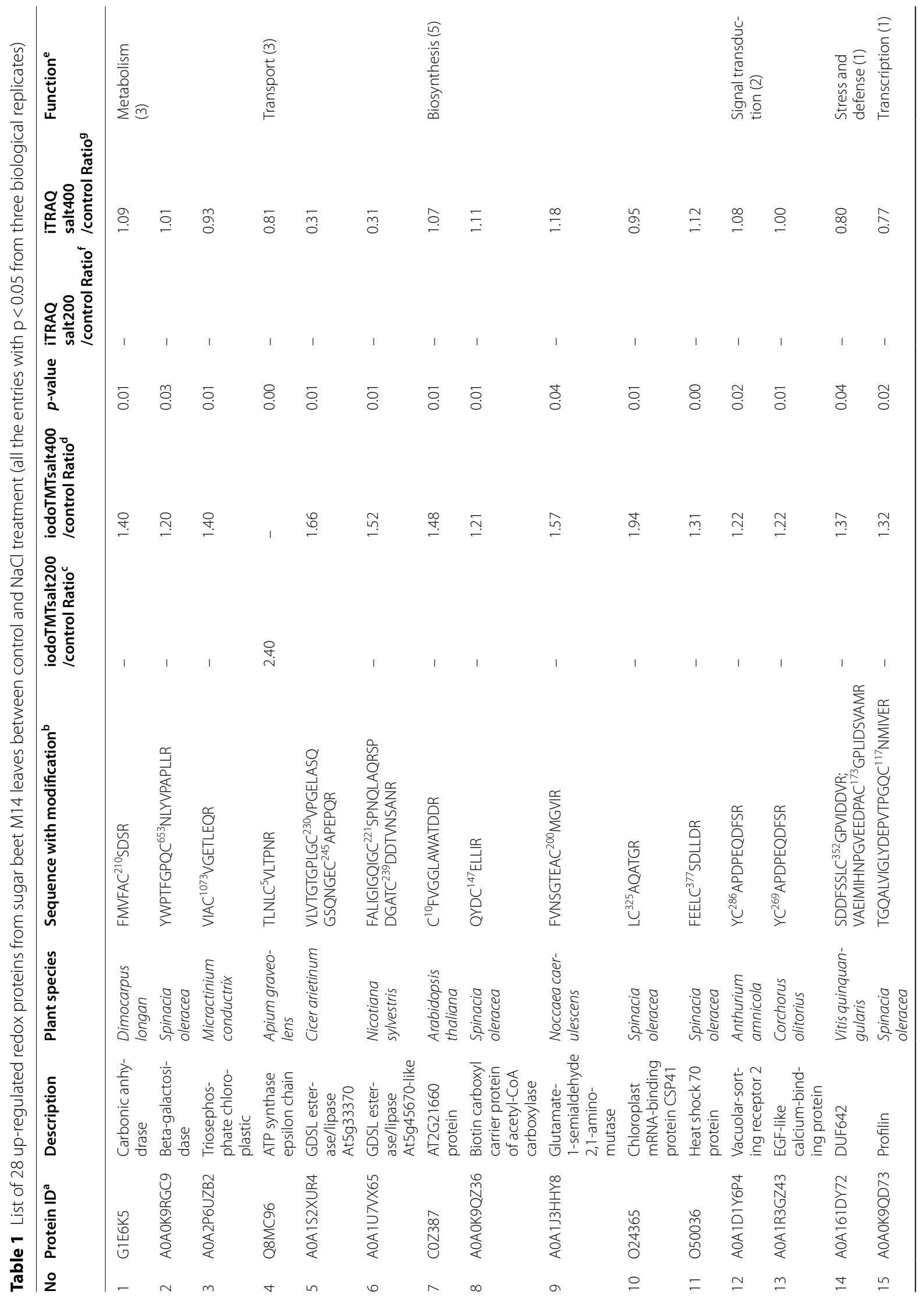




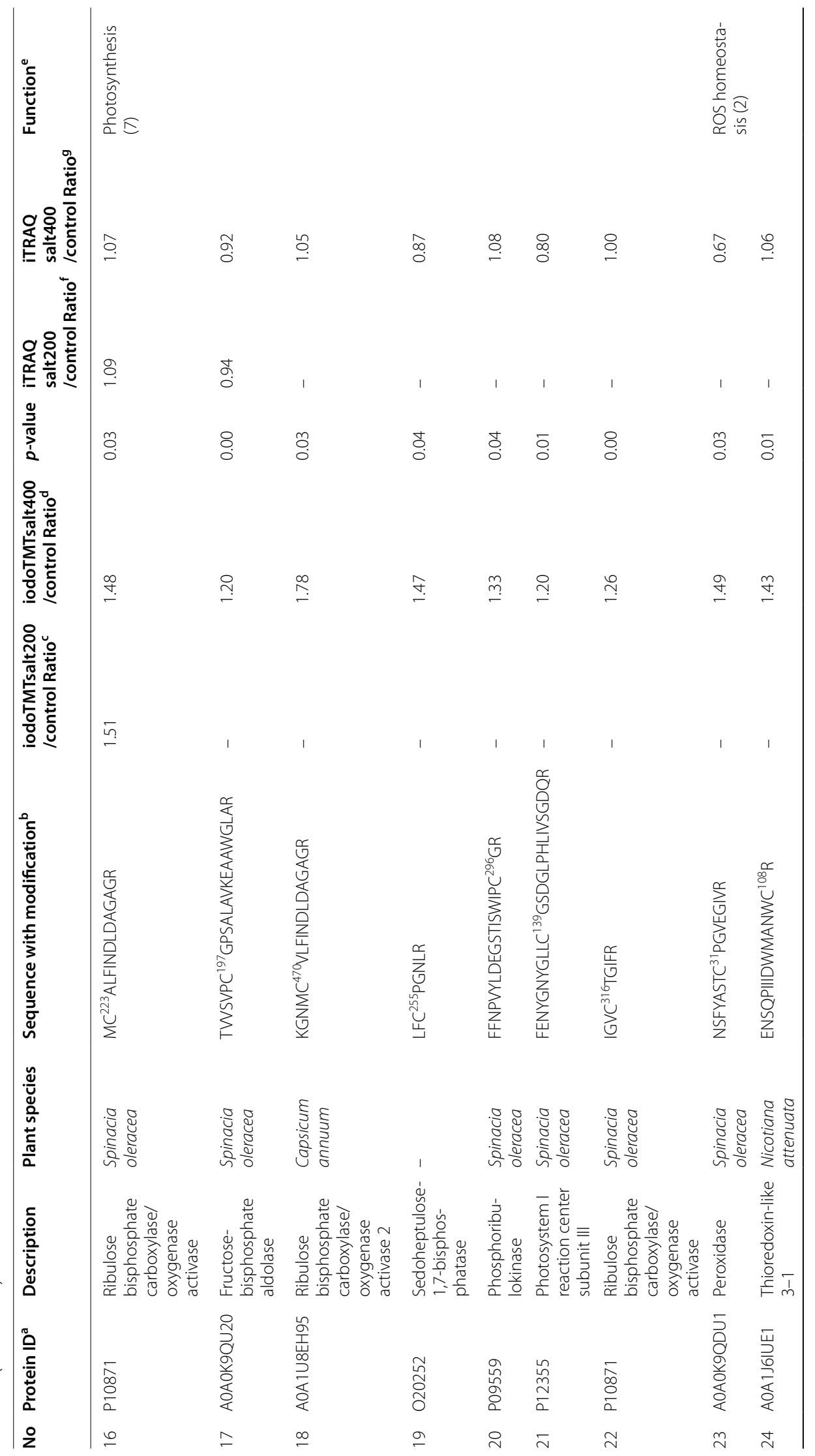




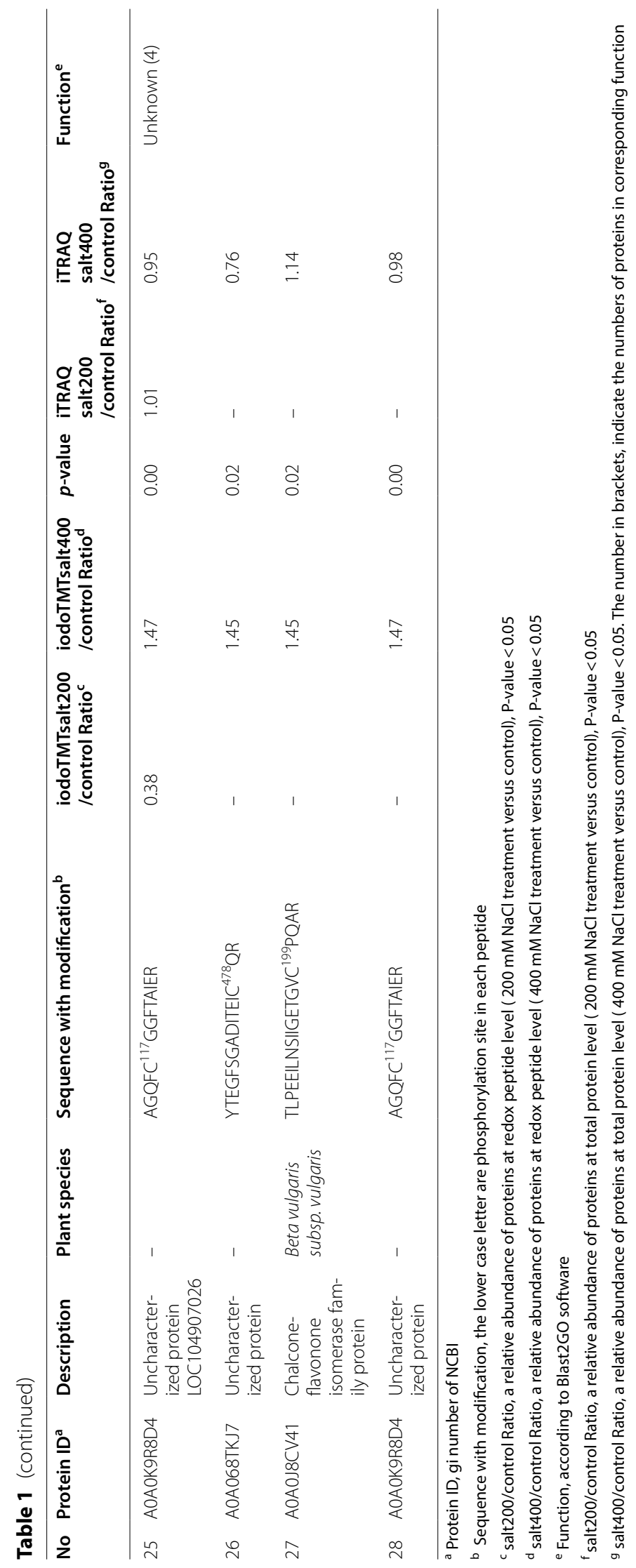




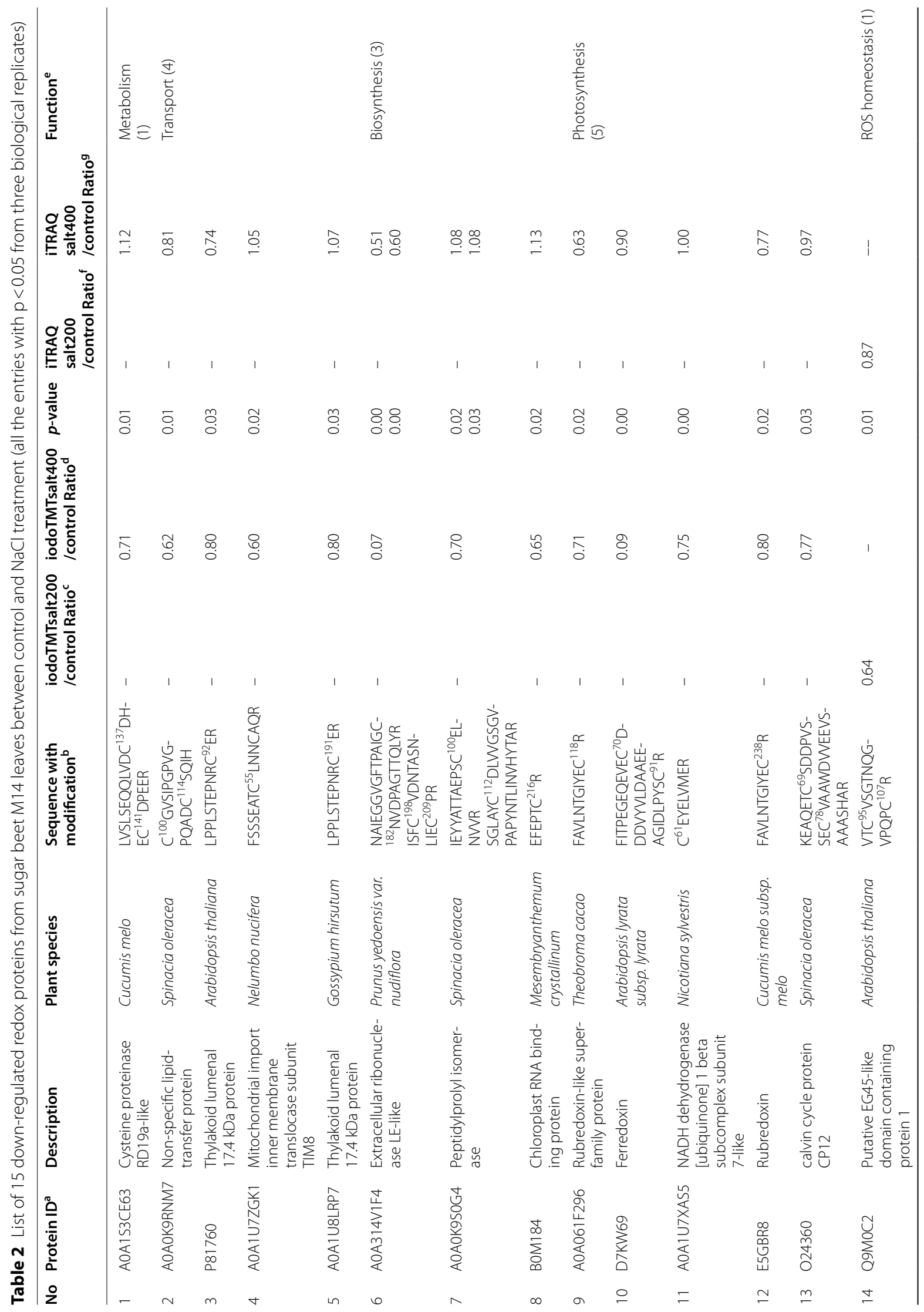




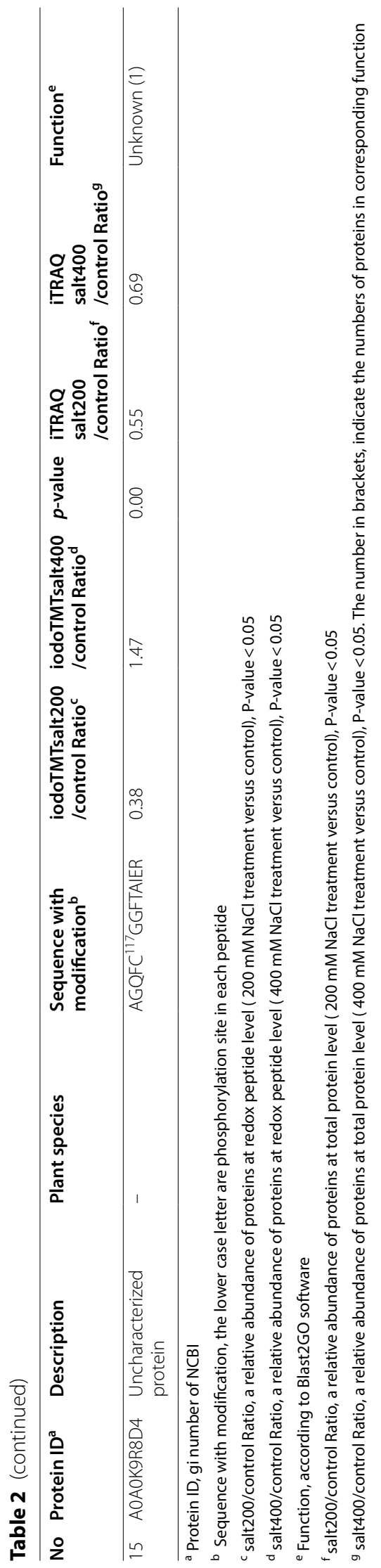




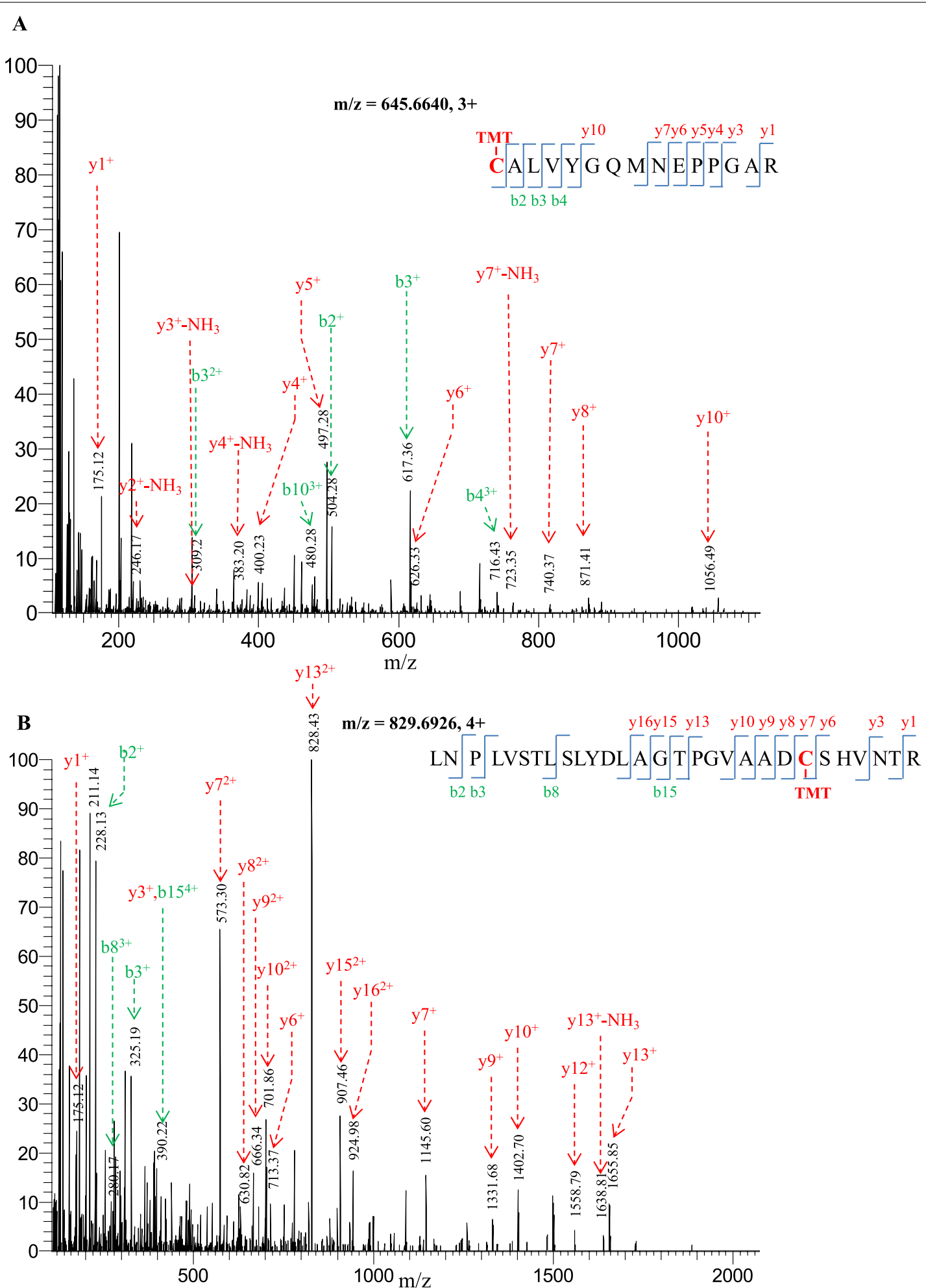

Fig.3 Example MS/MS spectra showing redox modified cysteine sites. A MS/MS spectrum of $C^{-T M T}$ ALVYGQMNEPPGAR derived from an ATP synthase $\mathbf{B}$ MS/MS spectrum of LNPLVSTLSLYDLAGTPGVAADC ${ }^{-T M T}$ SHVNTR derived from a malate dehydrogenase 


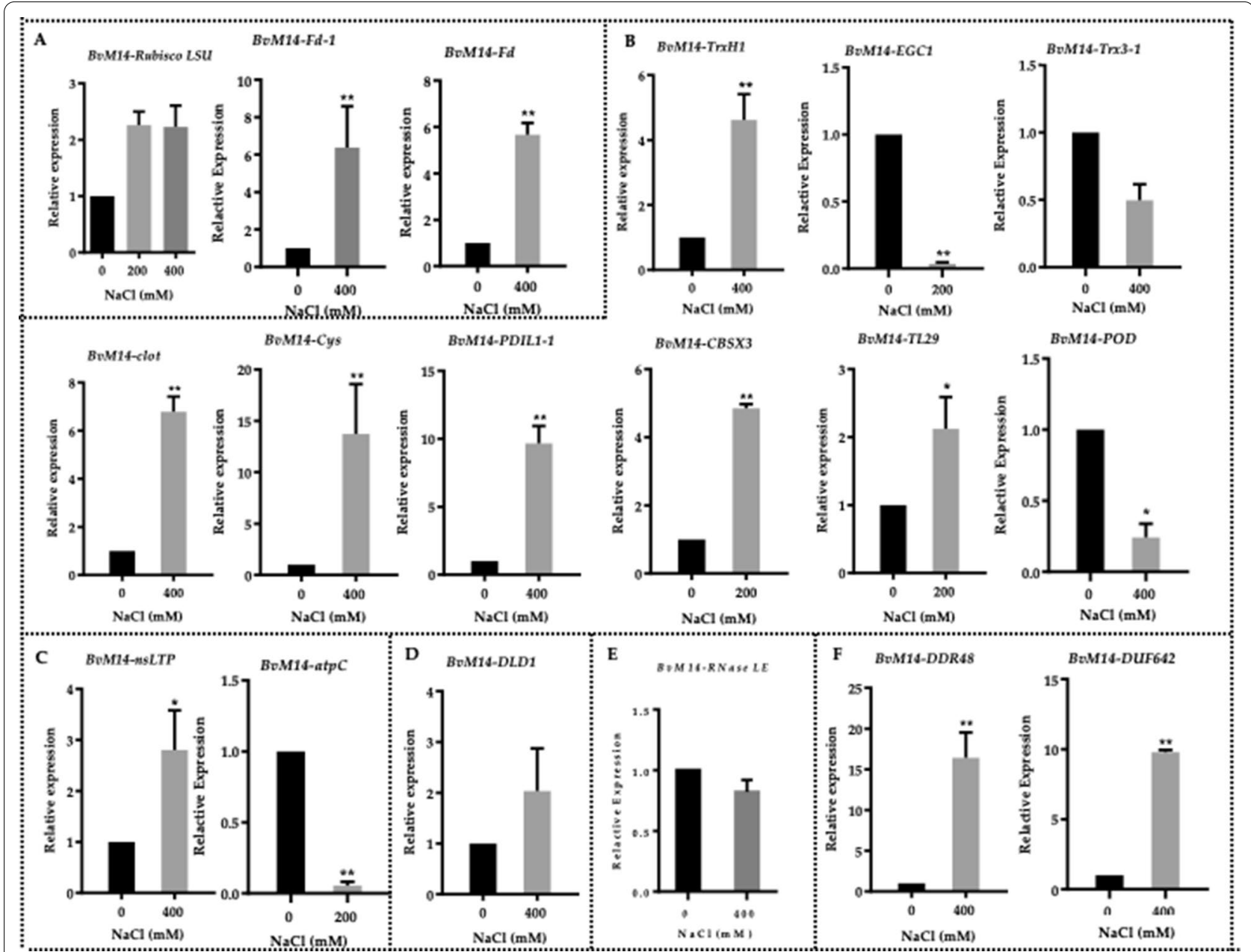

Fig.4 Real-time PCR analysis of the genes encoding the differential redox proteins and differential proteins in different pathways. A Photosynthesis, B ROS homeostasis, C Transport, D Metabolism, E Biosynthesis, and $\mathbf{F}$ Stress and defense. The $x$-axis is salt concentration. The $y$-axis is the relative expression of each gene $\left(2^{-\Delta \Delta C T}\right)$. Asterisks represent significant differences $\left({ }^{*} p<0.05,{ }^{* *} p<0.001\right)$ determined by one-way ANOVA followed by Tukey's HSD comparisons

(RNase LE), DUF642 and EG45-like domain containing protein $1(E G C 1)$ showed the same trend at both the protein level and transcriptional level (Additional file 7: Table S5).

\section{A review of potential salt stress response mechanisms in BvM14}

On the basis of the aforementioned results, we proposed a potential mechanism in the s BvM14 response to shortterm salt stress (Fig. 5, Additional file 8: Table S6). The differential redox proteins and total proteins put into context of subcellular locations and pathways under salt stress. The key pathways in Fig. 5 include ROS homeostasis, photosynthesis, stress and defense, transport related processes. Nevertheless, our results highlight the following potential mechanisms under salt stress: Salt stress leads to ROS production and oxidative stress, which lead to redox changes in microenvironment of cytoplasm and various organelles, resulting in redox PTMs of proteins in biochemical pathways dominated by photosynthesis and ROS homeostasis. The redox PTMs revealed in this study may play important regulatory roles in the $B v M 14$ salt stress response and contribute to the development of salt stress tolerance.

\section{Discussion}

Previous work has shown that BvM14 grew slowly and the leaves showed slightly chlorotic under $200 \mathrm{mM}$ and $400 \mathrm{mM} \mathrm{NaCl}$ treatment. Obviously, the growth phenotype of BvM14 under $400 \mathrm{mM} \mathrm{NaCl}$ treatment was suppressed (Yang et al. 2012, 2013). In this study, we have successfully applied the iodoTMTRAQ technology 


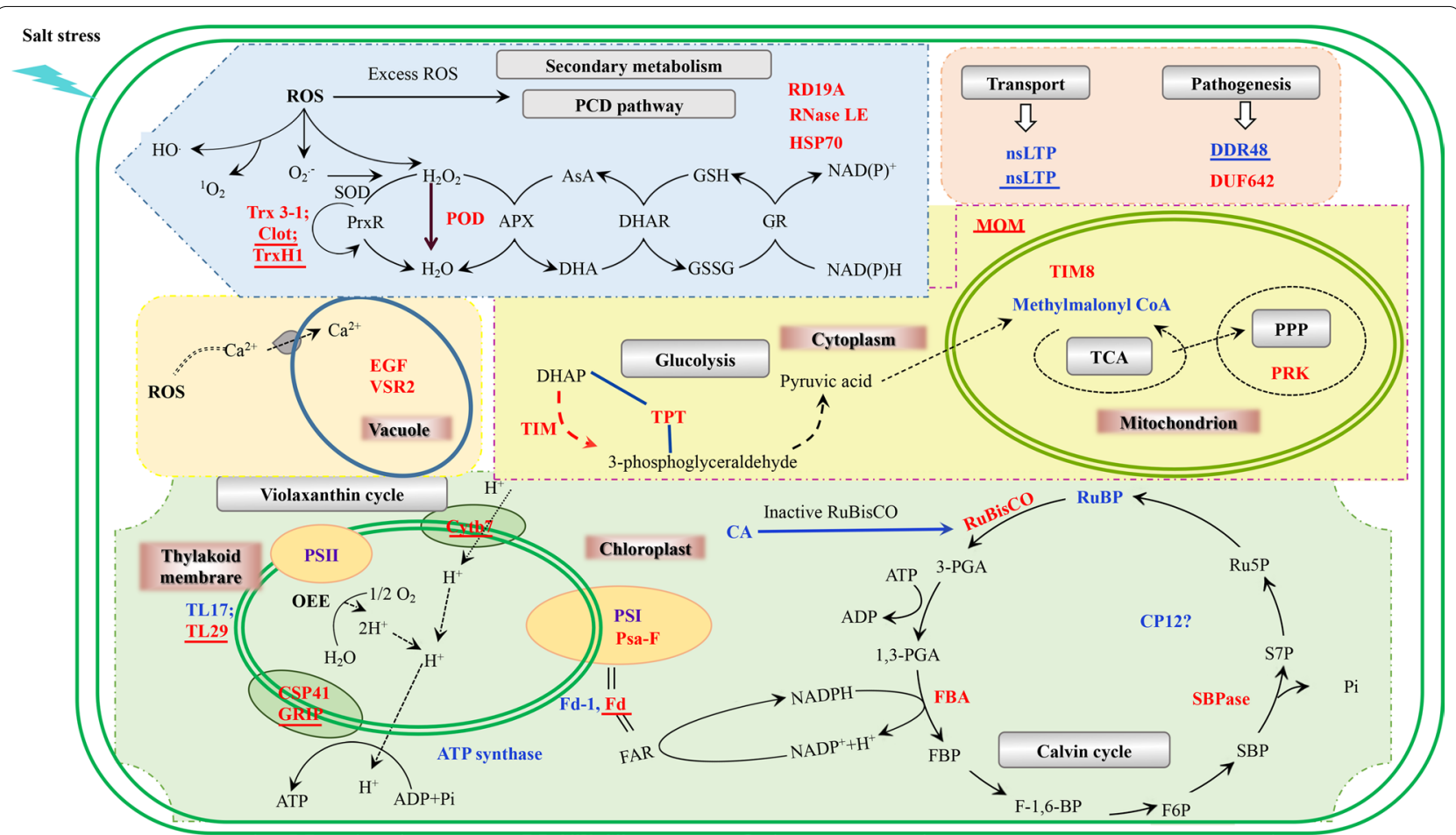

Fig.5 Schematic presentation of systematic salt tolerance mechanisms in BVM14 leaves. The identified proteins and redox-responsive proteins were put into subcellular locations and KEGG pathways. The red and blue colors indicate increased and decreased in redox PTMs, respectively, and those underlined red and blue highlight proteins with increased and decreased levels, respectively. Please refer to Additional file 8: Table S6 for protein IDs

and identified many interesting redox-responsive proteins in the processes of metabolism, transport, biosynthesis, transcription related, signal transduction, photosynthesis, stress and defense and ROS homeostasis. The iodoTMT signal from treated samples compared to control increased that indicate oxidation of sensitive cysteines. In the discussion sections, we focus on discussing total protein and redox protein changes that are important for understanding the $B v M 14$ salt stress response mechanisms.

\section{ROS homeostasis and protein redox PTMs in BvM14 response to salt stress}

In the $B v M 14$ leaves, three and six ROS homeostasis proteins were identified in redox proteomics and total proteomics, respectively (Tables 1, 2; Additional file 4: Table S2). For example, peroxidase (POD) and thioredoxin-like 3-1 (Trx3-1) increased in oxidation under $400 \mathrm{mM} \mathrm{NaCl}$ treatment. Other thioredoxins, such as Trx Clot (Clot) and TrxH1 increased at total protein level under the $400 \mathrm{mM} \mathrm{NaCl}$ treatment. Trxs are important players in the antioxidant defense system by inhibiting oxidative stress induced protein oxidation, which can also be triggered by other environmental stress factors (Miller et al. 2010). They modulate the target proteins' function by oxidoreductase activities (Meyer et al. 2012) and play critical regulatory roles in signal transduction under adverse environments (Kneeshaw et al. 2014; Mata-Pérez et al. 2019). A recent study has shown that AtTrx-h2 can improve Brassica napus's salt tolerance by increasing the activities of antioxidant enzymes and biomass. The AtTrx-h2 maybe a promising genetic resource to boost salt stress tolerance in plants. (Ji et al. 2020). In the special $B v \mathrm{M} 14$, both increased levels of $\operatorname{Tr} \mathrm{H} 1$ and increased redox PTMs seem to be required for enhancing the antioxidant system under salt stress. POD Clot proteins was first identified in Drosophila, it is an essential for the biosynthesis of drosopterin (an eye pigment) and the protein were supposed to be GSH-dependent enzymes (Giordano et al. 2003). Clot belongs to classes of atypical Trxs. However, in plants, how Clot plays a role in stress responses is not clear. Plants remove ROS by antioxidative enzymes except for Trxs, which protect plants from oxidative damage (Choudhury et al. 2017). APX, CAT, POD and SOD are key factors in plant under salt stress. Overexpression of their corresponding genes led to higher antioxidant enzyme activities and boost the ROS detoxification pathway related genes' expression compared to those in control plants under salt stress (Ahmad et al. 2008; Wang et al. 2009; Li et al. 2020). Two 
cystathionine- $\beta$-synthase domain-containing proteins (CBSX1 and CBSX2) were increased under salt stress. It was reported that CBSX1 and CBSX2 as the redox regulators can directly regulate the activation of Trxs in the chloroplasts. Overexpressed CBSX1 and CBSX2 can promoted plant growth and development by increasing Trxs, meanwhile they could modulate their target proteins (Jung et al. 2013; Yoo et al. 2011; Shin et al. 2020).

\section{Photosynthesis proteins in BvM14 response to salt stress}

Under salt stress, stomatal closure restricts carbon dioxide intake, and thus impaired photosynthesis. Stress tolerant plants can maintain capacity for photosynthesis to meet the energy need (Kosova et al. 2011). In this work, 12 and 4 photosynthesis proteins were identified in redox proteomics and in total proteomics, respectively (Table 1; Additional file 4: Table S2). The 12 photosynthesis proteins include rubredoxin (Rub), rubredoxin-like superfamily protein (Rubl), three ribulose bisphosphate carboxylases/oxygenase activases (Rubisco), photosystem I reaction center subunit III (PSI-RC), ferredoxin (Fd), fructose-bisphosphate aldolase(FBA), fedoheptulose-1,7-bisphosphatase (SBPase), phosphoribulokinase (PRK), Calvin cycle protein CP12 (CP12) and NADH dehydrogenase [ubiquinone] 1 beta subcomplex subunit 7-like (NDUFB7) (Table 1; Fig. 5, Additional file 4: Table S2). The Fds involved in photosynthesis reside within the thylakoids in the chloroplasts or at their cytoplasmic side in cyanobacteria. They are key components of the photosynthetic electron transport chain, acting as main donors of electrons to the regulatory redox protein thioredoxin (Hanke et al. 2013; Buchanan et al. 2005). Fds also mediate electrons to $\mathrm{O}_{2}$ (Mehler reaction) and to some of the cyclic electron transport pathways (Shahak et al. 1981; Shikanai et al. 2007; Strand et al. 2017; Marcus et al. 2020). In plants, ROS formation are in the electron transport chains (ETC) of the chloroplasts and the mitochondria. At low levels, ROS are key factors in physiological redox signaling when plants response to stresses, while on the contrary, they are associated with oxidative stress (Gómez et al. 2020). In photosystem I (PSI), the electron transport chain light energy is drived electrons to the acceptor molecule. Sedoheptulose-1,7-bisphosphatase (SBPase) plays key role in the Calvin cycle, which produces the substrate (RuBP) for Rubisco. The electrons of PSI reduce Fd by the enzyme ferredoxin/thioredoxin reductase, which in turn leads to the reduction of thioredoxin f, Finally, trxs activate the SBPase enzyme can promote Cys-52 and Cys-57 to form two thiol groups by reducing the disulfide bond between them (Christine et al. 1999). Redox regulation of the photosynthesis-related proteins has been well-known, but how they change in terms of protein levels and redox states under salt stress has been rarely reported.

\section{Stress and defense proteins in BvM14 response to salt stress}

Plants experiencing salt stress often exhibit osmotic stress, ionic stress and oxidative stress, which can lead to the accumulation of ROS and malondialdehyde (Jiang et al. 2020; Zhao et al. 2021). Moreever, stress and defense related proteins have been studied under adverse environments (Liu et al. 2018). Under salt stress, we identified stress protein DDR48 in total protein level and DUF642 protein in redox proteomics. In Arabidopsis, four DNA damage-inducible genes $(D D R)$ were induced under osmotic stress. These genes have two sets of different osmotic stress-inducible promoters. The DDR48 was regulated by a different promoter than the one operating in the other three genes under osmotic stress. One significant difference between the two sets of promoters is their sensitivity to different salt conditions (Miralles et al. 1995). As to DUF642, it was a positive regulator of pectin methylesterase (PME) activity (Zúñiga-Sánchez et al. 2014). The AhDGR2 gene, encoding the DUF642 protein, was significantly up-regulated in roots and leaves of young A. hypochondriacus plants under water-deficit and salt stress, suggesting its participation in abiotic stress resistance (Palmeros-Suárez et al. 2017). Here in $B v M 14$, we did not observe increase in DUF642 protein levels, but detected for the first time it was oxidized under $400 \mathrm{mM} \mathrm{NaCl}$. It is not known whether oxidation decreases or increases its activity.

\section{Transport proteins in BvM14 response to salt stress}

In this study, non-specific lipid-transfer protein (nsLTP), thylakoid luminal $17.4 \mathrm{kDa}$ protein (TL17) and mitochondrial import inner membrane translocase subunit (TIM8) were reduced in response to the salt stress. Mitochondrial outer membrane protein porin of $36 \mathrm{kDa}$ (MOM) and trigger factor-like protein (TIG) were increased at the protein level. To date, many LTPs have been described in multiple species, such as Arabidopsis, cotton, wheat, rice, and tobacco (Kinlaw et al. 1994; Kader et al. 1997; Feng et al. 2004; Liu et al. 2006; Boutrot et al. 2008). For example, overexpression a potato $n S L T P 1$ contributed to the reduced the accumulation of ROS induced by boosting the expression of antioxidant enzyme genes under adverse stresses (Gangadhar et al. 2016). In plants, like nucleus and chloroplasts, mitochondria have two membranes: outer and inner mitochondrial membranes. The existence of a double membrane capsule defines four kinds of mitochondrial sub-compartments with different structures and functions: mitochondrial outer membrane 
(MOM), mitochondrial inner membrane (MIM), inter membrane space (IMS) and matrix (Schneiter et al. 1999; Dukanovic et al. 2011). In this work, MOM and IMS translocase subunits (TIM8) were differential expressed. It was shown that protein import into mitochondria was changed under adverse stresses that also inhibited mitochondrial functions (Taylor et al. 2003). Arabidopsis mitochondrial proteomics also revealed negative effects of oxidative stress and respiratory inhibitors on important mitochondrial functions (Sweetlove et al. 2003).

\section{Transcriptional regulation of redox proteins and proteins in BvM14 response to salt stress}

The work showed many protein levels changes and redox level changes under salt stress treatments. Gene transcription can result in the protein level changes. In addition, stress and defense, ROS homeostasis and photosynthesis changes may be affected by redox protein level and protein level changes. The transcriptional levels of the 18 genes encoding for the proteins, the transcriptional level changes of 12 genes stayed in synchronization with the corresponding redox level trend and total protein level trend (Fig. 4, Additional file 4: Table S4), indicating interesting regulatory mechanisms at transcriptional level and PTM level. It should be noted that PTM studies in plant salt response are underrepresented in present knowledge. The identification and cysteine site-mapping of the 42 redox proteins in this work highlight the significance of redox PTMs in the BvM14 salt stress response (Additional file 9: Table S7).

\section{Conclusions}

The iodoTMTRAQ double labeling quantitative proteomics identified 1290 proteins in the $B v M 14$, of which 80 proteins and 42 redox-responsive proteins showed differential changes under salt stress. The salt-stress responsive proteins and redox modified proteins were mainly involved in metabolism, transport, biosynthesis, transcription related, signal transduction, stress and defense, ROS homeostasis and photosynthesis. The results have shown total protein changes and protein redox changes (with more than 53 redox sites in 42 proteins) in different cellular pathways and processes in the BvM14 plant short-term salt stress response. Obviously, the potential salt response mechanisms involve many different components, pathways and processes (Fig. 5). The interesting findings from this quantitative redox proteomics study include: (1) Several different proteins exhibited significant changes under short term salt stress, including thioredoxin-like 3-1, peroxidase and EG45-like domain containing proteins; (2) redox modifications responsive to the salt stress are not limited to ROS homeostasis and photosynthesis. They were distributed in key physiological processes including transport, transcription, metabolism, and stress and defense (Fig. 5). This explains how the $B v M 14$ plants can rapidly perceived salt stress, make appropriate changes in cellular biochemical and physiological processes, and adapt for long-term growth and development. As the phosphorylation study has discovered many novel proteins (Yu et al. 2016), this work on redox proteomics has revealed many redox responsive proteins and redox modifications. For example, reduction of extracellular ribonuclease LE-like and nsLTP is a novel discovery. For future research, we will focus on resolving the functional implication and significance of these redox PTM events in plant salt stress response and tolerance.

\section{Supplementary Information}

The online version contains supplementary material available at https://doi. org/10.1186/s40529-021-00320-x.

Additional file 1: Figure S1. Singular enrichment analysis (SEA) for redox proteins in biological process (A), cellular components (B) and molecular function (C) was conducted using AgriGO. Each box shows the GO term, $\mathrm{GO}$ description, the number mapping the $\mathrm{GO}$ and total number of query in the backgroud. Box color indicates levels of statistical significance. More statistically significant nodes result in darker red color.

Additional file 2: Figure S2. Singular enrichment analysis (SEA) for total proteins in biological process (A), cellular components (B) and molecular function (C) was conducted using AgriGO. Each box shows the GO term, $\mathrm{GO}$ description, the number mapping the $\mathrm{GO}$ and total number of query in the backgroud. Box color indicates levels of statistical significance. More statistically significant nodes result in darker red color.

Additional file 3: Table S1. List of the identified 1290 proteins from BvM14 leaves between control and NaCl treatment using LC-MS/MS.

Additional file 4: Table S2. List of 80 differentially expressed proteins from BVM14 leaves between control and NaCl treatment using LC-MS/MS.

Additional file 5: Table S3. List of 42 differential redox proteins from BvM14 leaves between control and NaCl treatment using LC-MS/MS.

Additional file 6: Table S4. List of the primer sequences for the 19 genes tested by qRT-PCR in Figure 4.

Additional file 7: Table S5. Transcriptional level, redox level and protein expressing pattern of seven differential redox proteins and 11 differential proteins.

Additional file 8: Table S6. List of protein IDs shown in Figure 5.

Additional file 9: Table S7. MS/MS spectra showing redox modified cysteine sites.

\section{Acknowledgements}

The paper represents serial 018 from our innovation team at the Heilongjiang University (Hdtd2010-05).

\section{Authors' contributions}

$\mathrm{J}$ : conducted proteomics experiments and written the first draft; $\mathrm{MJ}$ and $\mathrm{TZ}$ : conducted biochemical experiments and assisted with draft editing; $\mathrm{CY}$ and $\mathrm{HL}$ : conducted gene transcription analysis; SC: assisted with mass spectrometry and editing of the manuscript; $\mathrm{HL}$ and $\mathrm{KW}$ : assisted with experimental design, data analysis and supervision of experiments; HL: funding acquisition, project supervision and finalized the manuscript. All authors have read and agreed to the published version of the manuscript. 


\section{Funding}

This research was supported by the National Science Foundation of China (Project 32072122: The transcription factor BVGT-1 regulates the molecular mechanism of glyoxalase / gene involved in the salt tolerance of sugar beet M14) and Heilongjiang Provincial Department of Education, the basic scientific research business expenses of Heilongjiang provincial institutions of higher learning science and technology innovation special (key) item (Project KJCXZD201718: Establishment and Optimization of Sugar Beet Regeneration System).

\section{Availability of data and materials}

The data and materials used and analyzed in the current study can be provided by the corresponding author for scientific, non-profit purposes.

\section{Declarations}

\section{Ethics approval and consent to participate}

Not applicable, the study involves no human participants.

\section{Consent for publication}

Not applicable.

\section{Competing interests}

The authors declare that they have no competing interests.

\section{Author details}

${ }^{1}$ Ministry of Education, School of Chemistry and Materials Science, Heilongjiang University, Harbin 150080, China. ${ }^{2}$ Key Laboratory of Molecular Biology of Heilongjiang Province, College of Life Sciences, Heilongjiang University, Harbin 150080, China. ${ }^{3}$ Engineering Research Center of Agricultural Microbiology Technology, Ministry of Education, Heilongjiang University, Harbin 150080, China. ${ }^{4}$ Proteomics and Mass Spectrometry, Interdisciplinary Center for Biotechnology Research, University of Florida, Gainesville, FL 32610, USA. ${ }^{5}$ Department of Biology, Genetics Institute, Plant Molecular and Cellular Biology Program, University of Florida, Gainesville, FL 32610, USA.

Received: 26 May 2021 Accepted: 4 September 2021

Published online: 18 October 2021

\section{References}

Ahmad R, Kim MD, Back KH, Kim HS, Lee HS, Kwon SY (2008) Stress-induced expression of choline oxidase in potato plant chloroplasts confers enhanced tolerance to oxidative, salt, and drought stresses. Plant Cell Rep 27:687-698. https://doi.org/10.1007/s00299-007-0479-4

Baez NOD, Reisz JA, Furdui CM (2015) Mass spectrometry in studies of protein thiol chemistry and signaling: opportunities and caveats. Free Radic Biol Med 80:191-211. https://doi.org/10.1016/j.freeradbiomed

Boutrot F, Chantret N, Gautier MF (2008) Genome wide analysis of the rice and Arabidopsis non-specifific lipid transfer protein ( $n s L t p)$ gene families and identification of wheat nsLtp genes by EST data mining. BMC Genomics 9:86. https://doi.org/10.1186/1471-2164-9-86

Buchanan BB, Balmer Y (2005) Redox regulation: a broadening horizon. Annu Rev Plant Biol 56:187-206. https://doi.org/10.1146/annurev.arplant.56. 032604.144246

Chang IF, Hsu JL, Hsu PH, Sheng WA, Lai SJ, Lee C, Chen CW, Hsu JC, Wang SY, Wang LY, Chen CC (2012) Comparative phosphoproteomic analysis of microsomal fractions of Arabidopsis thaliana and Oryza sativa subjected to high salinity. Plant Sci 185-186:131-142. https://doi.org/10.1016/j. plantsci.2011.09.009

Choudhury FK, Rivero RM, Blumwald E, Mittler R (2017) Reactive oxygen species, abiotic stress and stress combination. Plant J 90:856-867. https://doi. org/10.1111/tpj.13299

Raines CA, Lloyd JC, Dyer TA (1999) New insights into the structure and function of sedoheptulose-1,7-bisphosphatase; an important but neglected Calvin cycle enzyme. J Exp Bot 330:1-8. https://doi.org/10.1093/jxb/50. 330.1

Claiborne A, Yeh Jl, Mallett TC, Luba J, Crane EJ, Charrier V, Parsonage D (2005) Protein-sulfenic acids: diverse roles for an unlikely player in enzyme catalysis and redox regulation. Biochemistry 38:15407-15416. https://doi. org/10.1021/big92025k

Conesa A, Götz S, García-Gómez JM, Terol J, Talón M, Robles M (2005) Blast2GO: a universal tool for annotation, visualization and analysis in functional genomics research. Bioinformatics 21:3674-3676. https://doi.org/10. 1093/bioinformatics/bti610

Dave R, Tripathi RD, Dwivedi S, Tripathi P, Dixit G, Sharma YK, Trivedi PK, Corpas FJ, Barroso JB, Chakrabarty D (2012) Arsenate and arsenite exposure modulate antioxidants and amino acids in contrasting arsenic accumulating rice (Oryza sativa L.) genotypes. Hazard Mater 15:1123-1131. https://doi. org/10.1016/j.jhazmat.2012.06.049

Dukanovic J, Rapaport D (2011) Multiple pathways in the integration of proteins into the mitochondrial outer membrane. Biochim Biophys Acta 1808:971-980. https://doi.org/10.1016/j.bbamem.2010.06.021

Farooq MA, Gill RA, Islam F, Ali B, Liu H, Xu J, He S, Zhou W (2016) Methyl jasmonate regulates antioxidant defense and suppresses arsenicuptake in Brassica napus L. Front Plant Sci 7:468. https://doi.org/10.3389/fpls. 2016.00468

Feng JX, Ji SJ, Shi YH, Wei G, Zhu YX (2004) Analysis of five differentially expressed gene families in fast elongating cotton fiber. Acta Biochim Biophys Sin 36:51-57. https://doi.org/10.1093/abbs/36.1.51

Gangadhar BH, Sajeesh K, Venkatesh J, Baskar V, Abhinandan K, Yu JW, Prasad R, Mishra RK (2016) Enhanced tolerance of transgenic potato plants over-expressing non-specific lipid transfer protein-1 (StnsLTP1) against multiple abiotic stresses. Front Plant Sci 7:1228. https://doi.org/10.3389/ fpls.2016.01228

Ghoulam C, Foursy A, Fares K (2002) Effects of salt stress on growth, inorganic ions and proline accumulation in relation to osmotic adjustment in five sugar beet cultivars. Environ Exp Bot 47:39-50. https://doi.org/10.1016/ S0098-8472(01)00109-5

Giordano E, Peluso I, Rendina R, Digilio A, Furia M (2003) The clot gene of Drosophila melanogaster encodes a conserved member of the thioredoxinlike protein superfamily. Mol Genet Genomics 268:692-697. https://doi. org/10.1007/s00438-002-0792-0

Gómez R, Figueroa N, Melzer M, Hajirezaei MR, Carrillo N, Lodeyro AF (2020) Photosynthetic characterization of flavodoxin-expressing tobacco plants reveals a high light acclimation-like phenotype. Biochim Biophys Acta Bioenerg 1861:148211. https://doi.org/10.1016/j.bbabio.2020.148211

Gupta V, Carroll KS (2013) Sulfenic acid chemistry, detection and cellular lifetime. Biochim Biophys Acta 2:847-875. https://doi.org/10.1016/j.bbagen. 2013.05.040

Hanke G, Mulo P (2013) Plant type ferredoxins and ferredoxin-dependent metabolism. Plant Cell Environ 36:1071-1084. https://doi.org/10.1111/ pce. 12046

Heppner DE, Janssen-Heininger YMW, Van der Vliet A (2017) The role of sulfenic acids in cellular redox signaling: reconciling chemical kinetics and molecular detection strategies. Arch Biochem Biophys 616:40-46. https://doi.org/10.1016/j.abb.2017.01.008

Heppner DE, Hristova M, Ida T, Mijuskovic A, Dustin CM, Bogdándi V, Fukuto JM, Dick TP, Nagy P, Li J, Akaike T, Vliet A (2018) Cysteine perthiosulfenic acid (Cys-SSOH): a novel intermediate in thiol-based redox signaling? Redox Biol 14:379-385. https://doi.org/10.1016/j.redox.2017.10.006

Howat D (2000) Acceptable salinity, sodicity and pH values for boreal forest reclamation. In: ESD. Alberta Environment, Edmonton Alberta. pp. 2-191.

Hsu JL, Wang LY, Wang SY, Lin CH, Ho KC, Shi FK, Chang IF (2009) Functional phosphoproteomic profiling of phosphorylation sites in membrane fractions of salt-stressed Arabidopsis thaliana. Proteome Sci 7:42. https://doi. org/10.1186/1477-5956-7-42

Ji D, Matthew J, Gaffrey WQ (2017) Quantitative proteomic characterization of redox-dependent post-translational modifications on protein cysteines. Mol Biosystem 13:807-1048. https://doi.org/10.1039/c6mb00861e

Ji MG, Park HJ, Cha JY, Kim JA, Shin GI, Jeong SY, Lee ES, Yun DJ, Lee SY, Kim WY (2020) Expression of Arabidopsis thaliana thioredoxin-h2 in Brassica napus enhances antioxidant defenses and improves salt tolerance. Plant Physiol Biochem 147:313-321. https://doi.org/10.1016/j.plaphy.2019.12.032

Jiang J, Ren X, Li L, Hou R, Sun W, Jiao C, Yang N, Dong Y (2020) $\mathrm{H}_{2}$ S Regulation of Metabolism in cucumber in response to salt-stress through transcriptome and proteome analysis. Front Plant Sci 11:1283. https://doi.org/10. 3389/fpls.2020.01283

Jung KW, Kim YY, Yoo KS, Ok SH, Cui MH, Jeong BC, Yoo SD, Jeung JU, Shin JS (2013) Acystathionine- $\beta$-synthase domain-containing protein, CBSX2, 
regulates endothecial secondary cell wall thickening in anther development. Plant Cell Physiol 54:195-208. https://doi.org/10.1093/pcp/pcs166

Jung HI, Kong MS, Lee BR, Kim TH, Chae MJ, Lee EJ, Jung GB, Lee CH, Sung JK, Kim YH (2019) Exogenous glutathione increases arsenic translocation into shoots and alleviates arsenic-induced oxidative stress by sustaining ascorbate-glutathione homeostasis in rice seedlings. Front Plant Sci 10:1089. https://doi.org/10.3389/fpls.2019.01089

Kader JC (1997) Lipid transfer proteins: a puzzling family of plant proteins. Trends Plant Sci 2:66-70. https://doi.org/10.1146/annurev.arplant.47.1.627

Kemp M, Go YM, Jones DP (2008) Nonequilibrium thermodynamics of thiol/ disulfide redox systems: a perspective on redox systems biology. Free Radic Biol Med 44:921-937. https://doi.org/10.1016/j.freeradbiomed. 2007.11 .008

Khan PSSV, Hoffmann L, Renaut J, Hausman JF (2007) Current initiatives in proteomics for the analysis of plant salt tolerance. Curr Sci 93:807-817

Khan MN, Siddiqui MH, AlSolami MA, Alamri S, Hu Y, Ali HM, Al-Amri AA, Alsubaie QD, Al-Mungedhi BMA, Al-Ghamdi A (2020) Crosstalk of hydrogen sulfide and nitric oxide requires calcium to mitigate impaired photosynthesis under cadmium stress by activating defense mechanisms in Vigna radiata. Plant Physiol Biochem 156:278-290. https://doi.org/10.1016/j. plaphy.2020.09.017

Kinlaw CS, Gerttula SM, Carter MC (1994) Lipid transfer protein genes of loblolly pine are members of a complex gene family. Plant Mol Biol 26:1213-1216. https://doi.org/10.1007/BF00040702

Kitajima S (2008) Hydrogen peroxide-mediated inactivation of two chloroplastic peroxidases, ascorbate peroxidase and 2-Cys peroxiredoxin. Photochem Photobiol 84:1404-1409. https://doi.org/10.1111/j.17511097.2008.00452.x

Kitajima S, Kurioka M, Yoshimoto T, Shindo M, Kanaori K, Tajima K, Oda K (2008) A cysteine residue near the propionate side chain of heme is the radical site in ascorbate peroxidase. FEBS J 3:470-480. https://doi.org/10.1111/j. $1742-4658.2007 .06214 . x$

Kneeshaw S, Gelineau S, TadaY LGJ, Spoel SH (2014) Selective protein denitrosylation activity of thioredoxin-h5 modulates plant immunity. Mol Cell 56:153-162. https://doi.org/10.1016/j.molcel.2014.08.003

Kosova K, Vitamvas P, Prasil IT, Renaut J (2011) Plant proteome changes under abiotic stress-contribution of proteomics studies to understanding plant stress response. J Proteomics 74:1301-1322. https://doi.org/10.1016/j. jprot.2011.02.006

Li H, Cao H, Wang Y, Pang Q, Ma C, Chen S (2009) Proteomic analysis of sugar beet apomictic monosomic addition line M14.J J Proteomics 73:297-308. https://doi.org/10.1016/j.jprot.2009.09.012

Li H, Pan Y, Zhang Y, Wu C, Ma C, Yu B, Zhu N, Koh J, Chen S (2015) Salt stress response of membrane proteome of Sugar beet monosomic addition line M14. J Proteomics 127:18-33. https://doi.org/10.1016/j.jprot.2015. 03.025

Li C, Ji J, Wang G, Li Z, Wang Y, Fan Y (2020) Over-expression of LCPDS, LCZDS, and LCCRTISO, genes from wolfberry for carotenoid biosynthesis, enhanced carotenoid accumulation, and salt tolerance in Tobacco. Front Plant Sci 11:119. https://doi.org/10.3389/fpls.2020.00119

Lin Y, Chen G, Lin H, Lin M, Wang H, Lin Y (2020) Chitosan postharvest treatment suppresses the pulp breakdown development of longan fruit through regulating ROS metabolism. Int J Biol Macromol 28:601-608. https://doi.org/10.1016/j.ijbiomac

Liu K, Jiang H, Moore S, Watkins C, Jahn M (2006) Isolation and characterization of a lipid transfer protein expressed in ripening fruit of Capsicum chinense. Planta 223:672-683. https://doi.org/10.1007/s00425-005-0120-0

Liu YL, Cao D, Ma LL, Jin XF, Yang PF, Ye F (2018) TMT-based quantitative proteomics analysis reveals the response of tea plant (Camellia sinensis) to fluoride. J Proteomics 176:71-81. https://doi.org/10.1016/j.jprot.2018. 02.001

Marcus Y, Gurevitz M (2020) Ferredoxin-mediated reduction of 2-nitrothiophene inhibits photosynthesis: mechanism and herbicidal potential. Biochem J 477:1149-1158. https://doi.org/10.1042/BCJ20190830

Mata-Pérez C, Spoel SH (2019) Thioredoxin-mediated redox signaling in plant immunity. Plant Sci 279:27-33. https://doi.org/10.1016/j.plantsci.2018. 05.001

Meyer Y, Belin C, Delorme-Hinoux V, Reichheld JP, Riondet C (2012) Thioredoxin and glutaredoxin systems in plants: molecular mechanisms, crosstalks, and functional significance. Antioxid Redox Signal 17:1124-1160. https:// doi.org/10.1089/ars.2011.4327
Miller G, Suzuki N, CIFTCI-YILMAZ S, MITTLER R, (2010) Reactive oxygen species homeostasis and signalling during drought and salinity stresses. Plant Cell Environ 33:453-467. https://doi.org/10.1111/j.1365-3040.2009. 02041.x

Miralles VJ, Serrano R (1995) A genomic locus in Saccharomyces cerevisiae with four genes up-regulated by osmotic stress. Mol Microbiol 17:653-662. https://doi.org/10.1111/j.1365-2958.1995.mmi_17040653.x

Mock HP, Dietz KJ (2016) Redox proteomics for the assessment of redoxrelated posttranslational regulation in plants. Biochim Biophys Acta 1864:967-973. https://doi.org/10.1016/j.bbapap.2016.01.005

Navrot N, Finnie C, Svensson B, Hägglund P (2011) Plant redox proteomics. J Proteomics 74:1450-1462. https://doi.org/10.1016/j.jprot.2011.03.008

Palmeros-Suárez PA, Massange-Sánchez JA, Sánchez-Segura L, MartínezGallardo NA, Espitia-Rangel E, Gómez-Leyva JF, Délano-Frier JP (2017) AhDGR2, an amaranth abiotic stress-induced DUF642 protein gene, modifies cell wall structure and composition and causes salt and ABA hyper-sensibility in transgenic Arabidopsis. Planta 245:623-640. https:// doi.org/10.1007/s00425-016-2635-y

Parker J, Zhu N, Zhu M, Chen S (2012) Profiling thiol redox proteome using isotope tagging mass spectrometry. J vis Exp 24:2-7. https://doi.org/10. $3791 / 3766$

Parker J, Balmant K, Zhu F, Zhu N, Chen S (2015) cysTMTRAQ-An integrative method for unbiased thiol based redox proteomics. Mol Cell Proteomics 14:237-242. https://doi.org/10.1074/mcp.0114.041772

Pichon M, Gaymard A, Josset L, Valette M, Millat G, Lina B, Escuret V (2017) Characterization of oseltamivir-resistant influenza virus populations in immunosuppressed patients using digital-droplet PCR: comparison with QPCR and next generation sequencing analysis. Antiviral Res 145:160167. https://doi.org/10.1016/j.antiviral.2017.07.021

Poole LB, Karplus PA, Claiborne A (2004) Protein sulfenic acids in redox signaling. Annu Rev Pharmacol Toxicol 44:325-347. https://doi.org/10.1146/ annurev.pharmtox.44.101802.121735

Schneiter R, Brugger B, Sandhoff R, Zellnig G, Leber A, Lampl M, Athenstaedt K, Hrastnik C, Eder S, Daum G, Paltauf F, Wieland FT, Kohlwein SD (1999) Electrospray ionization tandem mass spectrometry (ESI-MS/MS) analysis of the lipid molecular species composition of yeast subcellular membranes reveals acyl chain-based sorting/remodeling of distinct molecular species en route to the plasma membrane. J Cell Biol 146:741-754. https://doi.org/10.1083/jcb.146.4.741

Shahak Y, Crowther D, Hind G (1981) The involvement of ferredoxin-NADP+ reductase in cyclic electron transport in chloroplasts. Biochim Biophys Acta 636:234-243. https://doi.org/10.1016/j.jplph.2013.03.016

Shikanai T (2007) Cyclic electron transport around photosystem I: genetic approaches. Annu Rev Plant Biol 58:199-217. https://doi.org/10.1146/ annurev.arplant.58.091406.110525

Shin JS, So WM, Kim SY, Noh M, Hyoung S, Yoo KS, Shin JS (2020) CBSX3TrXo-2 regulates $\mathrm{ROS}$ generation of mitochondrial complex II (succinate dehydrogenase) in Arabidopsis. Plant Sci 294:1 10458. https://doi.org/10. 1016/j.plantsci.2020.110458

Strand DD, Fisher N, Kramer DM (2017) The higher plant plastid NAD(P)H dehydrogenase-like complex (NDH) is a high effificiency proton pump that increases ATP production by cyclic electron flow. J Biol Chem 292:11850-11860. https://doi.org/10.1074/jbc.M1 16.770792

Sweetlove LJ, Heazlewood JL, Herald V, Holtzapffel R, Day DA, Leaver CJ, Millar AH (2002) The impact of oxidative stress on Arabidopsis mitochondria. Plant J 32:891-904. https://doi.org/10.1046/j.1365-313x.2002.01474.x

Taylor NL, Rudhe C, Hulet JM, Lithgow T, Glaser E, Day DA, Millar AH, Whelan $J$ (2003) Environmental stresses inhibit and stimulate different protein import pathways in plant mitochondria. FEBS Lett 547:125-130. https:// doi.org/10.1016/s0014-5793(03)00691-4

Thamsen M, Jakob U (2011) The redoxome proteomic analysis of cellular redox networks. Curr Opin Chem Biol 15:113-119. https://doi.org/10.1016/j. cbpa.2010.11.013

Untergasser A, Nijveen H, Rao X, Bisseling T, Geurts R, Leunissen JA (2007) Primer3 Plus, an enhanced web interface to primer3. Nucleic Acids Res 35:71-74. https://doi.org/10.1093/nar/gkm306

Wakeel A, Asif AR, Pitann B, Schubert S (2011) Proteome analysis of sugar beet (Beta vulgaris $\mathrm{L}$.) elucidatas constitutive adaptation during the first phase of salt stress. J Plant Physiol 6:519-526. https://doi.org/10.1016/j.jplph. 2010.08.016 
Wang WB, Kim YH, Lee HS, Kim KY, Deng XP, Kwak SS (2009) Analysis of antioxidant enzyme activity during germination of alfalfa under salt and drought stresses. Plant Physiol Biochem 47:570-577. https://doi.org/10. 1016/j.plaphy.2009.02.009

Xu X, Wan W, Jiang G, Xi Y, Huang H, Cai J, Chang Y, Duan CG, Mangrauthia SK, Peng X, Zhu JK, Zhu G (2019) Nucleocytoplasmic trafficking of the Arabidopsis WD40 repeat protein XIW1 regulates ABI5 stability and abscisic acid responses. Mol Plant 12:1598-1611. https://doi.org/10.1016/j.molp. 2019.07.001

Yang Y, Guo Y (2018) Elucidating the molecular mechanisms mediating plant salt-stress responses. New Phytol 217:523-539. https://doi.org/10.1111/ nph.14920

Yang L, Ma C, Wang L, Chen S, Li H (2012) Salt stress induced proteome and transcriptome changes in sugar beet monosomic addition line M14. J Plant Physiol 169:839-850. https://doi.org/10.1016/j.jplph.2012.01.023

Yang L, Zhang Y, Zhu N, Koh J, Ma C, Pan Y, Yu B, Chen S, Li H (2013) Proteomic analysis of salt tolerance in sugar beet monosomic addition line M14. J Proteome Res 12:4931-4950. https://doi.org/10.1021/pr400177m

Yoo KS, Ok SH, Jeong BC, Jung KW, Cui MH, Hyoung S, Le MR, Song HK, Shin JS (2011) Single cystathionine beta-synthase domain-containing proteins modulate development by regulating the thioredoxin system in Arabidopsis. Plant Cell 23:3577-3594. https://doi.org/10.1105/tpc.111.089847

Yu B, Li J, Koh J, Dufresne C, Yang N, Qi S, Zhang Y, Ma C, Duong BV, Chen S, Li $H$ (2016) Quantitative proteomics and phosphoproteomics of sugar beet monosomic addition line M14 in response to salt stress. J Proteomics 143:286-297. https://doi.org/10.1016/j.jprot.2016.04.011

Yu J, Li Y, Qin Z, Guo S, Li Y, Miao Y, Song C, Chen S, Dai S (2020) Plant chloroplast stress response: insights from thiol redox proteomics. Antioxid Redox Signal 33:35-57. https://doi.org/10.1089/ars.2019.7823

Yuan L, Wang J, Xie S, Zhao M, Nie L, Zheng Y, Zhu S, Hou J, Chen G, Wang $C$ (2019) Comparative proteomics indicates that redox homeostasis is involved in high- and low-temperature stress tolerance in a novel wucai (Brassica campestris L.) Genotype. Int J Mol Sci 15:3760. https://doi.org/10. 3390/ijms20153760

Zhao S, Zhang Q, Liu M, Zhou H, Ma C, Wang P (2021) Regulation of plant responses to salt stress. Int J Mol Sci 22(9):4609. https://doi.org/10.3390/ ijms22094609

Zúñiga-Sánchez E, Soriano D, Martínez-Barajas E, Orozco-Segovia A, GamboadeBuen A (2014) BIIDXI, the At4g32460 DUF642 gene, is involved in pectin methylesterase regulation during Arabidopsis thaliana seed germination and plant development. BMC Plant Biol 14:338. https://doi.org/10.1186/ s12870-014-0338-8

\section{Publisher's Note}

Springer Nature remains neutral with regard to jurisdictional claims in published maps and institutional affiliations.

\section{Submit your manuscript to a SpringerOpen ${ }^{\odot}$ journal and benefit from:}

- Convenient online submission

- Rigorous peer review

- Open access: articles freely available online

- High visibility within the field

- Retaining the copyright to your article

Submit your next manuscript at $\boldsymbol{\nabla}$ springeropen.com 